\title{
Weaning from prolonged veno-venous extracorporeal membrane oxygenation (ECMO) after transfer to a specialized center: a retrospective study
}

\author{
Frederik Seiler ${ }^{1}$. Franziska C. Trudzinski ${ }^{1} \cdot$ Sabrina I. Hörsch ${ }^{2}$ - Annegret Kamp ${ }^{1}$ - Carlos Metz ${ }^{1}$ Monika Flaig ${ }^{1}$. \\ Mohammad Alqudrah $^{1} \cdot$ Holger Wehrfritz $^{1} \cdot$ Markus Kredel $^{4} \cdot$ Ralf M. Muellenbach $^{3,4} \cdot$ Hendrik Haake $^{5}$. \\ Robert Bals ${ }^{1}$. Philipp M. Lepper ${ }^{1}$
}

Received: 11 December 2017 / Accepted: 8 May 2018 / Published online: 15 May 2018

(c) The Japanese Society for Artificial Organs 2018

\begin{abstract}
Veno-venous extracorporeal membrane oxygenation (vvECMO) is increasingly used as rescue therapy in severe respiratory failure. In patients with pre-existent lung diseases or persistent lung injury weaning from vvECMO can be challenging. This study sought to investigate outcomes of patients transferred to a specialized ECMO center after prolonged ECMO therapy. We performed a retrospective analysis of all patients admitted to our medical intensive care unit (ICU) between 01/2013 and 12/2016 who were transferred from an external ICU after $>8$ days on vvECMO. 12 patients on ECMO for $>8$ days were identified. Prior to transfer, patients underwent ECMO therapy for $18 \pm 9.5$ days. Total time on ECMO was $60 \pm 46.6$ days. $11 / 12$ patients could be successfully weaned from ECMO, $7 / 12$ in the first 28 days after transfer $(8 \pm 8.8$ ECMO-free days at day 28). In 7 patients, ECMO could be terminated after at least partial lung recovery, in 4 patients after salvage lung transplant. No patient died or needed re-initiation of ECMO therapy at day 28. In summary, weaning from vvECMO was feasible even after prolonged ECMO courses and salvage lung transplant could be avoided in most cases. Patients may benefit from transfer to a specialized ECMO center.
\end{abstract}

Keywords ECMO $\cdot$ Weaning $\cdot$ ARDS $\cdot$ Respiratory failure $\cdot$ Lung failure $\cdot$ Lung transplant

Philipp M. Lepper

philipp.lepper@uks.eu

1 Department of Internal Medicine V, Pneumology, Allergology, and Critical Care Medicine, Saarland University Medical Center, 66421 Homburg, Germany

2 Department of Anesthesiology, Critical Care Medicine, and Pain Therapy, Saarland University Medical Center, Homburg, Germany

3 Department of Anesthesiology, Critical Care Medicine, and Pain Therapy, Campus Kassel of the University of Southampton, Kassel, Germany

4 Department of Anesthesia and Critical Care, University Hospital of Würzburg, Würzburg, Germany

5 Division of Cardiology, Electrophysiology and Intensive Care Medicine, Kliniken Maria Hilf, Mönchengladbach, Germany

\section{Introduction}

In the context of invasive mechanical ventilation (IMV), the management of weaning is acknowledged as a complex process and an integral part of modern intensive care. Standardized weaning protocols are widely used and the institutionalization of specialized reference centers for patients difficult to wean from IMV is well established. In contrast, current knowledge about weaning from veno-venous extracorporeal membrane oxygenation (vvECMO) is sparse. In recent years, utilization of vvECMO as a rescue therapy in lung failure has been increasing worldwide $[1,2]$. Notably, vvECMO is also used in patients with pre-existent lung disease in cases of acute-on-chronic respiratory failure [3]. Bridging to recovery in its narrow sense is not always feasible in these patients [3]. Thus, weaning from vvECMO in patients with pre-existent lung disease or residual lung injury after initial resuscitation becomes a growing challenge. 
In this retrospective study, we analyzed a series of patients who were referred to our center after more than 8 days on vvECMO for ECMO weaning with the possibility of salvage lung transplant (LTX).

\section{Methods}

\section{Study setting and design}

All patient data presented in this study were acquired at the Saarland University Medical Center, a tertiary care hospital and supra-regional ECMO center in southwest Germany. The setting of the study was the medical ICU of the Department of Pneumology, Allergology and Critical Care Medicine at Saarland University Medical Center. Patient registries were screened for patients admitted between 01/2013 and $12 / 2016$ meeting the following criteria: (i) patient underwent vvECMO, (ii) vvECMO was initiated at an ICU other than the study center ICU, (iii) vvECMO duration prior to transfer to the study center ICU was more than 8 days. Patients on veno-arterial ECMO, hybrid configurations and low flow vvECMO for carbon dioxide removal were not analyzed. The following variables were analyzed at the time of presentation (day 1), day 2, day 5, and immediately prior to (day $x$ ) and/or at day 1 (day $x+1$ ) after termination of ECMO therapy: ECMO parameters (blood flow, sweep gas flow), ventilator settings [inspiratory plateau pressure $\left(P_{\text {insp }}\right)$, positive end-expiratory pressure (PEEP), fraction of inspired oxygen $\left(\mathrm{FIO}_{2}\right)$ ], and laboratory parameters [C-reactive protein (CRP), hemoglobin ( $\mathrm{Hb})$, white blood cell count (WBC), lactate, $\left.\mathrm{P}_{\mathrm{a}} \mathrm{O}_{2}, \mathrm{P}_{\mathrm{a}} \mathrm{CO}_{2}, \mathrm{pH}\right]$. In addition, total fluid balance from the time of presentation to the time of ECMO termination was determined. To assess outcomes, the following parameters were evaluated: successful weaning from ECMO at day 28 after bridging to recovery, termination of ECMO after salvage LTX, ECMO-free days at day 28, mortality at day 28 , in-hospital mortality, and recurrent need for ECMO therapy at day 28 and in-hospital. The necessity for informed consent was waived by the institutional review board (Ärztekammer des Saarlandes) due to the retrospective nature of the study.

\section{ECMO weaning}

ECMO weaning was managed upon individual order of the treating intensivist in charge. Generally, the following guidelines were used: ECMO weaning was attempted whenever possible, with $\mathrm{P}_{\mathrm{a}} \mathrm{O}_{2}, \mathrm{P}_{\mathrm{a}} \mathrm{CO}_{2}$, and $\mathrm{pH}$ being aimed to be kept within physiological range. Generally, ECMO weaning was given priority over IMV weaning. Blood flow was gradually reduced as far as tolerable until a blood flow of about $2 \mathrm{lpm}$ was reached. Sweep gas flow was reduced as far as tolerable until a gas flow of $1 \mathrm{lpm}$ was reached. In the case of stable oxygenation and absence of respiratory acidosis, sweep gas flow was stopped for a minimum of $1 \mathrm{~h}$; if gas exchange remained sufficient, ECMO therapy was discontinued.

\section{Data processing}

Statistical analysis was performed using the software SPSS 24 (IBM, Armonk NY, USA). Data were analyzed using Mann-Whitney $U$ test or Fisher's exact test, as appropriate. $P$ values $<0.05$ were considered statistically significant. Figures were created using the software Prism 5 (GraphPad Software, San Diego CA, USA).

\section{Results}

\section{Baseline characteristics}

During the defined study period, a total of 107 patients underwent vvECMO. Patients on vA-ECMO, hybrid configurations and low-flow ECMO for extracorporeal carbon dioxide removal were excluded. 32 vvECMO patients already were on ECMO at arrival, with cannulation performed either by the treating physicians of the referring hospital or by the mobile ECMO team of Saarland University Medical Center. Eventually, twelve patients were identified who underwent vvECMO for more than 8 days prior to transfer to the study center and were included to retrospective data analysis (Fig. 1a). As shown in Fig. 1b, we observed an increase of patients meeting the inclusion criteria in the last months with $8 / 12$ patients being transferred since January 2016.

Baseline data of the study subjects are shown in Table 1. The mean age was $42.5 \pm 15.29$ years. Patients in whom lung recovery occurred were significantly younger than patients requiring salvage LTX or who died on ECMO. 11/12 patients were male. In 4/12 patients, lung failure initially occurred due to ARDS with no previous history of lung disease. In $8 / 12$ patients, lung failure was caused by deterioration of a pre-existent chronic lung disease, namely interstitial lung diseases (3/12), cystic fibrosis (2/12), non-CF bronchiectasis $(2 / 12)$, or chronic obstructive lung disease (1/12). At the time of presentation at our ICU, patients already received ECMO therapy for $18(9-35) \pm 9.5$ days. Vascular access was established via the femoral vein (drainage cannula) and the internal jugular vein (return cannula) in 11/12 patients. In one case, patient was interfaced with the extracorporeal circuit via a $24 \mathrm{~F}$ dual lumen cannula in the left femoral vein. 11/12 patients received IMV. All patients on IMV underwent tracheostomy. One patient received continuous noninvasive ventilation. Only pressure-controlled ventilation modes were used. 
A

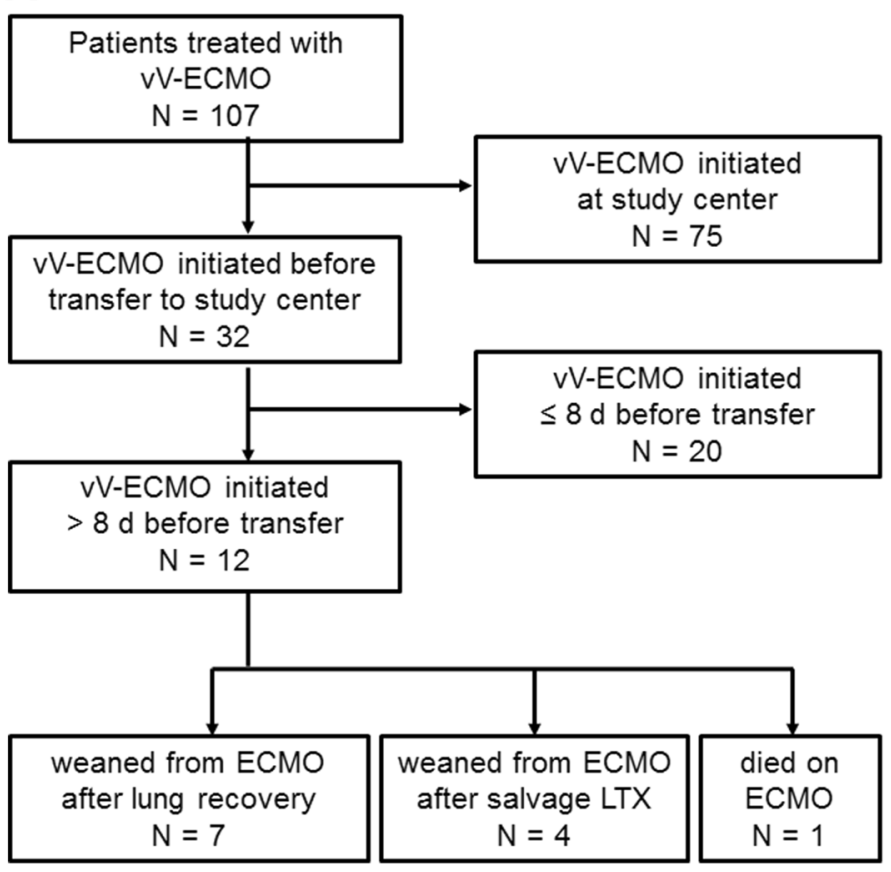

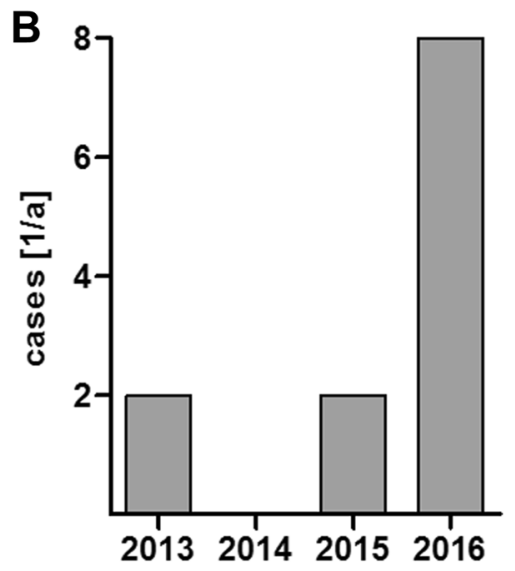

Fig. 1 a Flow chart presenting all patients included in the present study, b temporal distribution of recruitments within the study period

Table 1 Baseline data

\begin{tabular}{llllll}
\hline Parameter & Unit & All patients & Lung recovery & $\begin{array}{l}\text { Salvage LTX or } \\
\text { death on ECMO }\end{array}$ & $p$ value \\
\hline$N$ & & 12 & 7 & 5 & \\
Age & Years & $42.5 \pm 15.29$ & $35.4 \pm 15.7$ & $52.4 \pm 11.3$ & 0.048 \\
Male & & 11 & 6 & 5 & 1.000 \\
ECMO duration at arrival & Days & $18 \pm 9.5$ & $17 \pm 9.5$ & $19 \pm 10.5$ & 0.755 \\
IMV & & 11 & 6 & 5 & 1.000 \\
Tracheostomy & & 11 & 6 & 5 & 1.000 \\
Core-10-TISS & & $17.5 \pm 4.8$ & $16.1 \pm 3.0$ & $19.4 \pm 6.4$ & 0.432 \\
SAPS II & & $33.0 \pm 8.1$ & $33.9 \pm 7.6$ & $31.8 \pm 9.5$ & 0.876 \\
Blood flow & $\mathrm{lpm}$ & $3.86 \pm 1.28$ & $3.41 \pm 1.30$ & $4.49 \pm 1.04$ & 0.149 \\
Sweep flow & $\mathrm{lpm}$ & $6.4 \pm 3.1$ & $6.7 \pm 4.0$ & $6.0 \pm 1.2$ & 1.000 \\
$P_{\text {insp }}$ & $\mathrm{cmH} \mathrm{H}_{2} \mathrm{O}$ & $24.6 \pm 4.5$ & $24.3 \pm 4.5$ & $25.0 \pm 5.0$ & 0.876 \\
PEEP & $\mathrm{cmH} \mathrm{O}$ & $9.9 \pm 3.2$ & $9.7 \pm 3.5$ & $10.2 \pm 3.0$ & 0.755 \\
FIO ${ }_{2}$ & & $0.70 \pm 0.20$ & $0.66 \pm 0.23$ & $0.76 \pm 0.15$ & 0.530 \\
CRP & $\mathrm{mg} / 1$ & $93.0 \pm 99.5$ & $58.9 \pm 23.3$ & $140.7 \pm 146.7$ & 1.000 \\
WBC & $\mathrm{k} / \mu \mathrm{l}$ & $10.4 \pm 4.2$ & $11.4 \pm 5.1$ & $9.0 \pm 2.3$ & 0.639 \\
Lactate & $\mathrm{mmol} / 1$ & $1.2 \pm 0.6$ & $1.0 \pm 0.3$ & $1.3 \pm 0.9$ & 1.000 \\
Hemoglobin & $\mathrm{g} / \mathrm{dl}$ & $9.0 \pm 1.2$ & $8.6 \pm 1.1$ & $9.5 \pm 1.3$ & 0.343 \\
History of lung disease & & 8 & 5 & 3 & 1.000 \\
No history of lung disease & & 4 & 2 & 2 & 1.000 \\
\hline
\end{tabular}

Data are presented as number or mean $\pm \mathrm{SD}$, as appropriate. Statistical analysis was performed using the Mann-Whitney $U$ test or Fisher's exact test, as appropriate. $P$ values $<0.05$ (shown in italics) were considered statistically significant

ECMO extracorporeal membrane oxygenation, IMV invasive mechanical ventilation, TISS therapeutic intervention scoring system, SAPS II simplified acute physiology score 2 nd version, $P_{\text {insp }}$ : inspiratory plateau pressure, $\mathrm{PEEP}$ positive end-expiratory pressure, $\mathrm{FIO}_{2}$ fraction of inhaled oxygen, $\mathrm{CRP}$ C-reactive protein, $W B C$ white blood cell count 


\section{Clinical data}

At the time of presentation, patients received ECMO with a blood flow of $3.86 \pm 1.28 \mathrm{lpm}$ and a sweep gas flow of $6.4 \pm 3.1 \mathrm{lpm}$. Changes in blood and sweep gas flow over time are shown in Fig. 2. In the first 5 days upon referral, no substantial changes in either of the ECMO parameters were made. Before termination of ECMO therapy, blood flow was $1.84 \pm 0.40 \mathrm{lpm}$ and sweep gas flow was $1.5 \pm 2.4 \mathrm{lpm}$.

Figure $3 \mathrm{~A}$ shows changes in ventilator settings over time. At the time of presentation, patients were ventilated with an inspiratory pressure of $24.6 \pm 5.0 \mathrm{cmH}_{2} \mathrm{O}$ and a positive end-expiratory pressure (PEEP) of $9.9 \pm 3.2 \mathrm{cmH}_{2} \mathrm{O}$. $\mathrm{FIO}_{2}$ was $0.70 \pm 0.20$, as shown in Fig. 3b, with a resulting $\mathrm{P} / \mathrm{F}$ ratio (defined as $\mathrm{P}_{\mathrm{a}} \mathrm{O}_{2} / \mathrm{FIO}_{2}$ ) of $141 \pm 73$. Ventilator settings were only marginally changed in the first 5 days, with a trend towards slight reduction of inspiratory pressure and $\mathrm{FIO}_{2}$. Before termination of ECMO therapy, inspiratory pressure was $20.3 \pm 3.0 \mathrm{cmH}_{2} \mathrm{O}$, PEEP was $6.3 \pm 1.6 \mathrm{cmH}_{2} \mathrm{O}$, and $\mathrm{FIO}_{2}$ was $0.43 \pm 0.13$. $\mathrm{pH}$ and $\mathrm{p}_{\mathrm{a}} \mathrm{CO}_{2}$ were kept within physiological ranges during the ECMO course (Fig. 3c). After
Fig. 2 Times curves of the ECMO parameters blood flow (a) and sweep gas flow (b) in liters per minute (LPM) at the day of presentation $(\mathrm{d} 1)$, at day $2(\mathrm{~d} 2)$, day $5(\mathrm{~d} 5)$, and before termination of ECMO therapy $(\mathrm{d} x)$. Data are shown as mean \pm SD. $N=12(\mathrm{~d} 1, \mathrm{~d} 2, \mathrm{~d} 5)$ or $N=11(\mathrm{~d} x)$
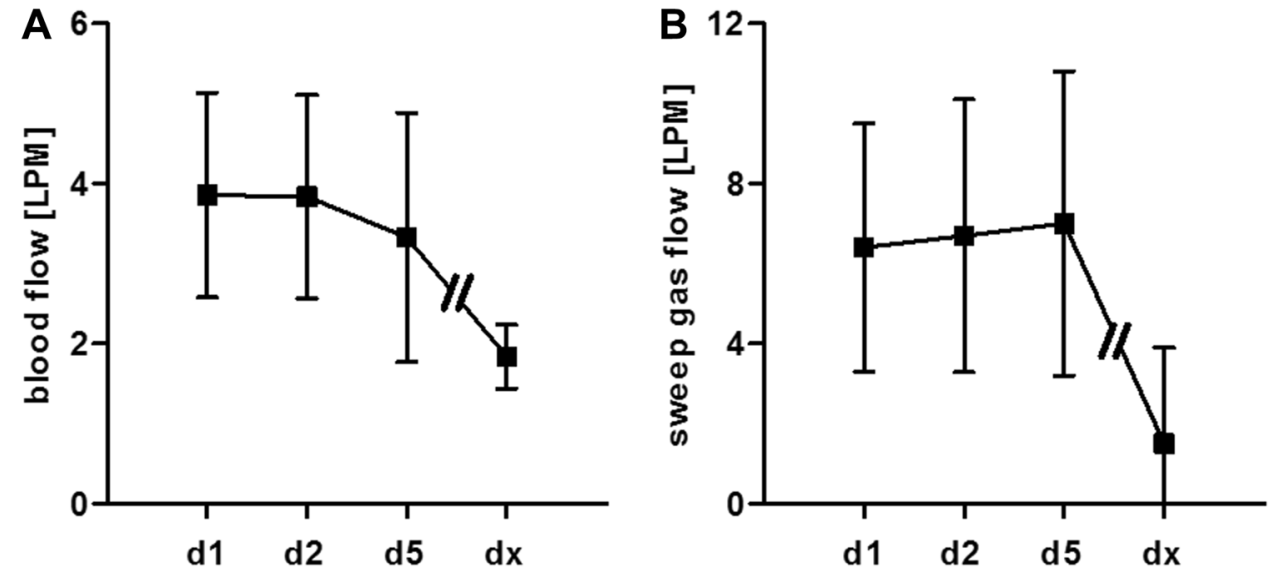
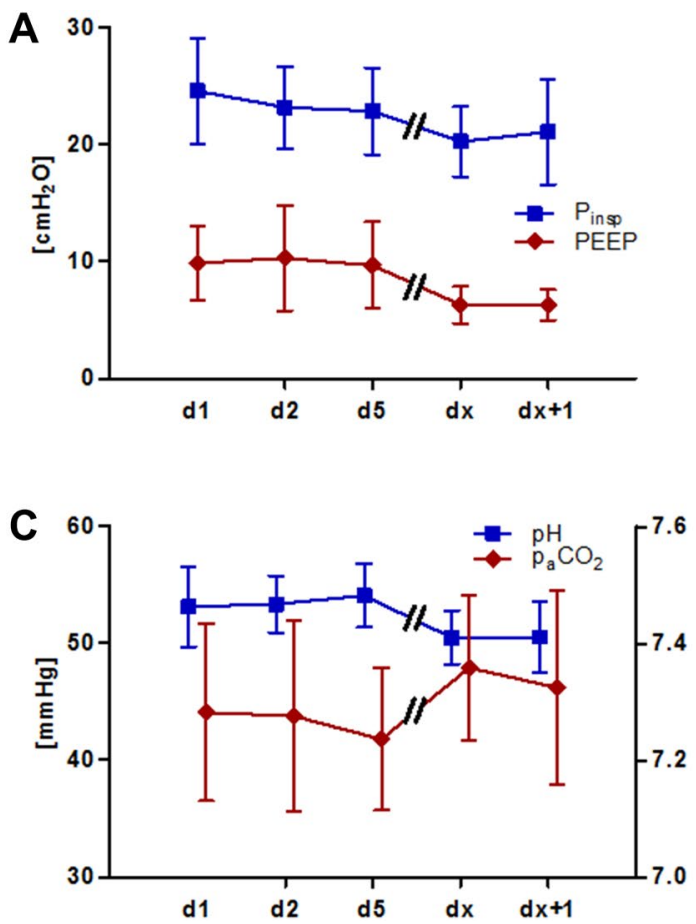

Fig. 3 Time curves of inspiratory pressure $\left(P_{\text {insp }}\right)$ and positive endexpiratory pressure (PEEP) (A), fraction of inspiratory oxygen $\left(\mathrm{FIO}_{2}\right)$ and $\mathrm{P} / \mathrm{F}$ ratio $\left(\mathrm{P}_{\mathrm{a}} \mathrm{O}_{2} / \mathrm{FIO}_{2}\right)(\mathrm{B}), \mathrm{pH}$ and $\mathrm{p}_{\mathrm{a}} \mathrm{CO}_{2}(\mathrm{C})$, or C-reactive protein (CRP) and hemoglobin ( $\mathrm{Hb})$ levels (D), respectively. Data are
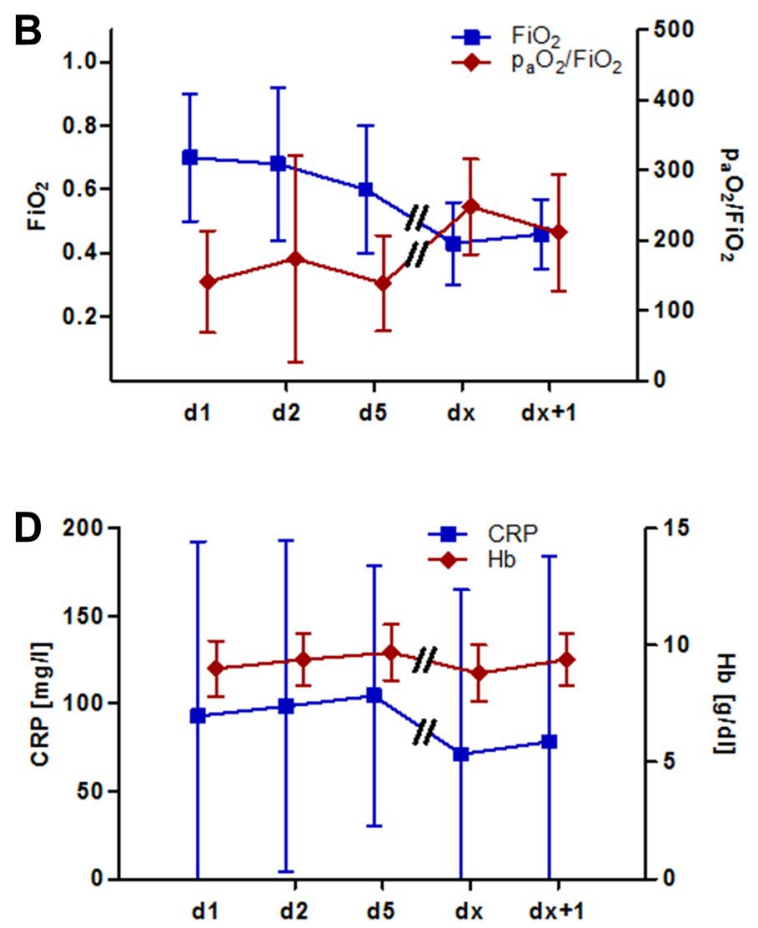

shown from the day of presentation (d1), day 2 (d2), day 5 (d5), day before termination of ECMO therapy $(\mathrm{d} x)$, and day 1 after termination of ECMO therapy $(\mathrm{d} x+1)$. Data are shown as mean \pm SD. $N=12$ $(\mathrm{d} 1, \mathrm{~d} 2, \mathrm{~d} 5)$ or $N=11(\mathrm{~d} x, \mathrm{~d} x+1)$ 
termination of ECMO therapy, moderate permissive hypercapnia was tolerated.

Patients in whom ECMO therapy could be terminated after successful bridging to recovery had a negative fluid balance at the time of ECMO termination $(-8.8 \pm 7.2 \mathrm{~L}$, Table 2). Patients who underwent salvage LTX or died on ECMO had a positive mean fluid balance $(+3.2 \pm 27.9 \mathrm{~L})$. However, there was no significant difference between both groups ( $p=0.202)$. As shown in Fig. 3d, CRP and Hb levels did not show consistent changes over time.

\section{Outcomes}

Upon referral, ECMO therapy was continued for 41 (7-135) \pm 42.6 days, which resulted in a total ECMO runtime of $60(16-170) \pm 46.6$ days (Table 2). One patient, who was not eligible for LTX, could not be weaned and died after 170 days on ECMO. 11/12 patients could be successfully weaned off ECMO. In seven patients, weaning was possible after-at least partial-lung recovery, in four patients, ECMO therapy could only be terminated after salvage lung transplant. Of note, all patients in whom lung recovery occurred were weaned within the first 28 days upon referral. In contrast, patients who could not be weaned within the first 28 days upon referral either required salvage LTX or died. No patient died at day 28 . In-hospital mortality was $16.67 \%$. At day 28 , no patient who was successfully weaned needed re-initiation of ECMO therapy. In four initially weaned patients, ECMO therapy had to be eventually re-initiated during their hospital stay; three of them underwent salvage LTX later on. $5 / 8$ patients with pre-existent lung disease could be weaned off device. None of them needed re-initiation of ECMO therapy with 28 days. $3 / 8$ needed ECMO later on in their course; all were successfully bridged to LTX finally. Figure 4 shows Kaplan-Meier plots of survival and ECMO duration.

Table 2 Patient outcomes and complications during ECMO

\begin{tabular}{|c|c|c|c|c|c|}
\hline Parameters & Unit & All patients & Lung recovery & $\begin{array}{l}\text { Salvage LTX or death } \\
\text { on ECMO }\end{array}$ & $p$ value \\
\hline$N$ & & 12 & 7 & 5 & \\
\hline ECMO duration after arrival & Days & $41 \pm 42.6$ & $15 \pm 7.6$ & $79 \pm 44.0$ & 0.003 \\
\hline ECMO duration total & Days & $60 \pm 46.6$ & $32 \pm 14.1$ & $98 \pm 50.6$ & 0.003 \\
\hline ECMO-free days at day 28 & & $8 \pm 8.8$ & $13 \pm 7.6$ & $0 \pm 0$ & 0.003 \\
\hline Weaned off device at day 28 & & 7 & 7 & 0 & 0.001 \\
\hline Mortality at day 28 & & 0 & 0 & 0 & \\
\hline Mortality in-hospital & & 2 & 1 & 1 & 1.000 \\
\hline Recurrent ECMO at day 28 & & 0 & 0 & 0 & \\
\hline Recurrent ECMO in-hospital & & 4 & 4 & 0 & 0.194 \\
\hline Lung transplantation & & 7 & 3 & 4 & 1.000 \\
\hline Thrombocytopenia $<50 / \mathrm{nl}$ & & 2 & 1 & 1 & 1.000 \\
\hline Thrombocytopenia $<100 /$ nl & & 8 & 3 & 5 & 0.081 \\
\hline Bleeding requiring transfusion $>2 \mathrm{PRBC}$ & & 7 & 2 & 5 & 0.028 \\
\hline Bleeding requiring transfusion $>4 \mathrm{PRBC}$ & & 0 & 0 & 0 & \\
\hline Bleeding requring surgical intervention & & 0 & 0 & 0 & \\
\hline Intracranial bleeding & & 0 & 0 & 0 & \\
\hline Fatal bleeding & & 0 & 0 & 0 & \\
\hline Heparin-induced thrombocytopenia ${ }^{a}$ & & 0 & 0 & 0 & \\
\hline Venous thrombosis $^{\mathrm{b}}$ & & 3 & 1 & 2 & 0.523 \\
\hline Pulmonary embolism ${ }^{c}$ & & 0 & 0 & 0 & \\
\hline CPR & & 2 & 0 & 2 & 0.152 \\
\hline Fluid balance & Liters & $-3.8 \pm 18.7$ & $-8.8 \pm 7.2$ & $+3.2 \pm 27.9$ & 0.202 \\
\hline
\end{tabular}

Data are presented as number or mean $\pm \mathrm{SD}$, as appropriate. Statistical analysis was performed using the Mann-Whitney $U$ test or Fisher's exact test, as appropriate. $p$ values $<0.05$ (shown in italics) were considered statistically significant

ECMO Extracorporeal membrane oxygenation, $P R B C$ packed red blood cells, $C P R$ cardiopulmonary resuscitation

${ }^{a}$ Verified by heparin-induced platelet aggregation test

${ }^{\mathrm{b}}$ Verified by ultrasonography or computer tomography

${ }^{\mathrm{c}}$ Verified by computer tomography 

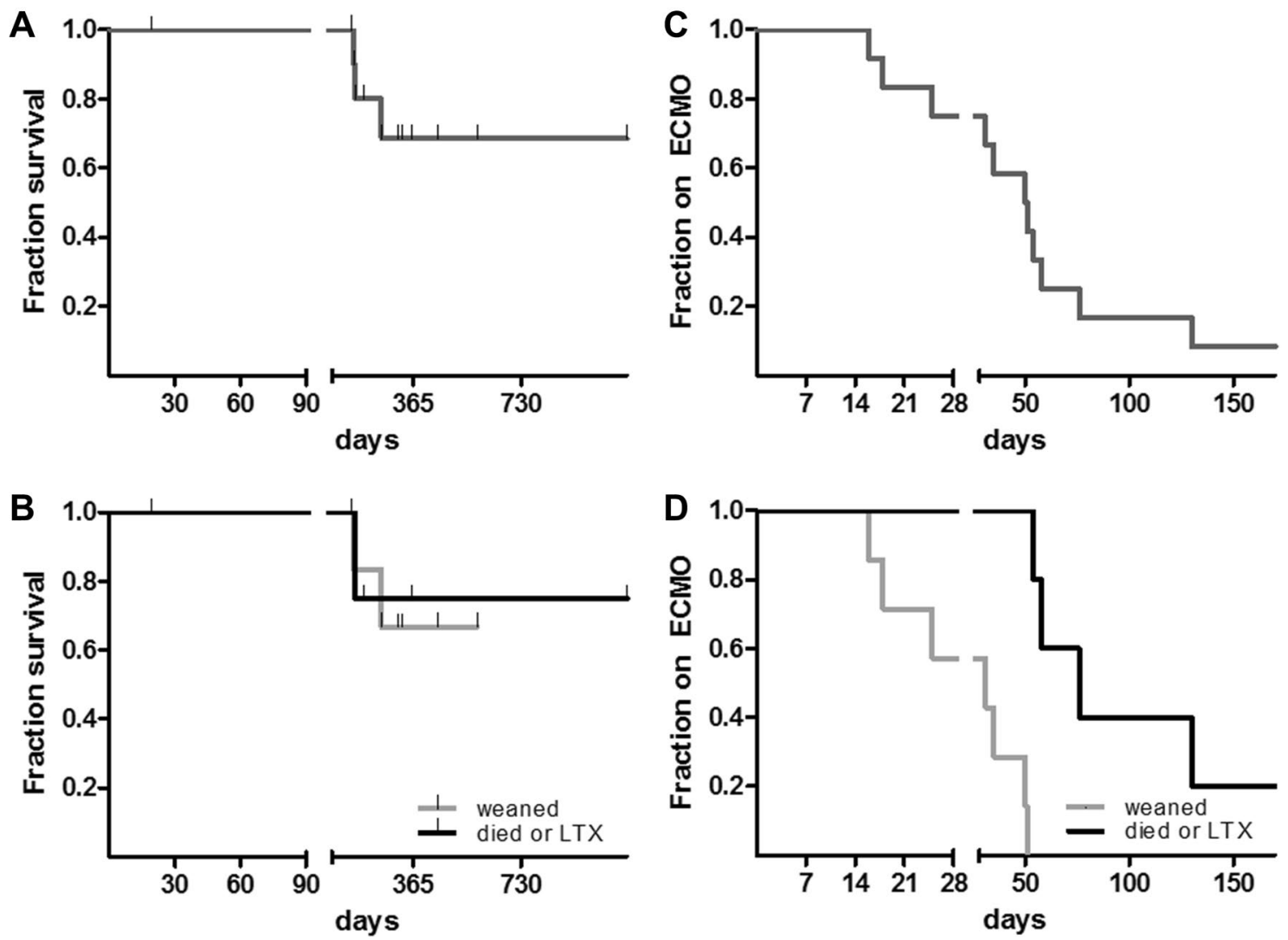

Fig. 4 Kaplan-Meier plots of a total survival $(N=12)$; b survival of patients weaned after lung recovery (weaned, $N=7$ ) versus patients undergoing salvage LTX or died on ECMO (died or LTX, $N=5$ ); c total duration of ECMO therapy $(N=12)$; $\mathbf{d}$ duration of ECMO ther-

\section{Discussion}

The main findings of our present study are: (i) weaning from vvECMO after prolonged courses is feasible, and (ii) substantial changes in the ECMO configurations in the initial phase after transfer were not achievable. In recent years, our center registered repeated requests from external hospitals seeking for referral of patients with prolonged ECMO courses, especially with regard to the possibility of salvage LTX. By their treating physicians who established ECMO, these patients were considered to suffer from "ECMO weaning failure". In the absence of an accepted consensus definition of this term, the diagnosis of ECMO weaning failure as a reason for referral was based on the subjective impression of the treating physicians in the referring hospitals. The number of patients transferred to our center after such requests particularly increased in the last months. This retrospective study aimed to investigate the outcomes of patients referred after a history of more than 8 days on ECMO before transfer to our ICU. A total of twelve patients fulfilled the inclusion criteria; $7 / 12$ patients were referred by university or comparable

apy in patients weaned after lung recovery (weaned, $N=7$ ) versus patients undergoing salvage LTX or died on ECMO (died or LTX, $N=5$ )

tertiary care centers. This small cohort represents a highly selected group of relatively young patients who either had no history of lung disease and were therefore considered to have potential for lung recovery, or who were initially considered eligible for LTX.

Nowadays, ECMO is considered an established procedure in the management of hypoxemic lung failure. An epidemiologic study from Germany demonstrated an increase in the use of ECMO in respiratory failure since 2007, with 2.4 cases per 100,000 inhabitants in 2014 [2]. In this work, as well as in other published studies, duration of ECMO for respiratory support did not exceed 10 days in the majority of patients $[2,4,5]$. In the CESAR trial, which provided the strongest evidence in favor of the usage of ECMO in severe ARDS so far, median duration of ECMO therapy was 9 days [6]. A recent Korean study reported a median ECMO duration of 7.4 days in patients who could be successfully weaned [7]. However, data from the international registry of the Extracorporeal Life Support Organization showed that in $22 \%$ of the patients duration of ECMO therapy exceeded 14 days [8]. Single reports on successful weaning after exceptionally prolonged ECMO therapy exist [5, 7, 9-11]. 
In the present report, patients already underwent prolonged ECMO courses of $18 \pm 9.5$ days before arrival. ECMO was continued for additional $41 \pm 42.6$ days. The primary goal in all patients was bridging to recovery whenever feasible. In patients with end stage lung disease, ECMO was utilized to sustain life until salvage LTX was possible. In all patients, regardless whether they were candidates for LTX, we aimed to wean off ECMO whenever possible. 11/12 patients could be weaned successfully, seven after at least partial lung recovery, four after salvage LTX. One patient died after 170 days on ECMO. Of those weaned off device, three patients underwent LTX later on. By weaning these patients from ECMO before LTX, ECMO-related complications may be reduced and the risks of salvage LTX with ongoing ECMO therapy can be avoided. Furthermore, mobilization pre-transplant is facilitated, and a thorough reconditioning can be realized.

In the present study, it was difficult to identify specific measures that enabled successful ECMO weaning. In some cases, sufficient anti-infective management or treatment of anemia may have crucially contributed to successful ECMO weaning; however, altogether neither laboratory markers of infection nor hemoglobin levels did seem to have a prognostic effect in this small collective.

Fluid balance is increasingly recognized as an important parameter in intensive care, and positive fluid balance is associated with worse outcomes in various groups of ICU patients, especially those with sepsis and septic shock [12, 13]. In the current analysis, the weaning process of patients bridged to lung recovery included a marked negative fluid balance of $-8.8 \pm 7.2 \mathrm{~L}$. However, there was no difference regarding fluid balance compared to patients who died or needed salvage LTX. Further studies are required to evaluate the role of fluid balance in ECMO weaning.

In contrast to countries such as the United Kingdom, where ECMO is only provided in few specialized centers, there are no such restrictions in the German healthcare system, allowing ECMO therapy also in low volume centers. There is also no obligation to disclose data on ECMO volume or outcomes. Therefore, the experience of the referring centers, which ranged from community hospitals to tertiary care and university centers, is not clear in all cases, making it difficult to identify skill differences compared to our center.

In fact, there are conflicting data on the impact of case volume on mortality of ECMO patients [14, 15]. Yet, a recently published statement by an international expert panel recommended that ECMO should only be provided by experienced centers with at least twenty cases per year [16]. Our current small hypothesis-generating report further adds the question, whether patients who already are on ECMO could benefit from a secondary transfer to a specialized ECMO center, especially if early weaning from ECMO cannot be realized. In line with the available literature on prolonged
ECMO courses, our current data suggest that gaining as much time as possible to enable native lung recovery, while preventing or managing multi-organ failure and ECMOrelated complications, may be the central determinant for successful weaning in these unique cases rather than single therapeutic measures. Therefore, a thorough center experience in the general management of individuals on ECMO may contribute to keep patients alive without severe complications until lung recovery or lung transplant.

\section{Conclusions}

Patients undergoing prolonged ECMO therapy with difficult ECMO weaning represent a small and heterogeneous subset, but the relevance of this population will probably increase with the abundant use of the procedure. Therefore, ECMOweaning protocols should be established analogous to IMV, and criteria for difficult, prolonged, and failed weaning from ECMO should be defined. In addition, future studies should aim to identify predictors for successful ECMO weaning.

Acknowledgements We thank the caregivers of the UKS-ECMO team for the special care of the patients that were entrusted to our care.

\section{Compliance with ethical standards}

Conflict of interest MK received honoraria from Getinge. The other authors declare no conflict of interest.

\section{References}

1. Sauer CM, Yuh DD, Bonde P. Extracorporeal membrane oxygenation use has increased by $433 \%$ in adults in the United States from 2006 to 2011. ASAIO J. 2015;61:31-6.

2. Karagiannidis C, Brodie D, Strassmann S, Stoelben E, Philipp A, Bein T, et al. Extracorporeal membrane oxygenation: evolving epidemiology and mortality. Intensive Care Med. 2016;42:889-96.

3. Trudzinski FC, Kaestner F, Schäfers H-J, Fähndrich S, Seiler F, Böhmer $\mathrm{P}$, et al. Outcome of patients with interstitial lung disease treated with extracorporeal membrane oxygenation for acute respiratory failure. Am J Respir Crit Care Med. 2016;193:527-33.

4. Aubron C, Cheng AC, Pilcher D, Leong T, Magrin G, Cooper DJ, et al. Factors associated with outcomes of patients on extracorporeal membrane oxygenation support: a 5-year cohort study. Crit Care. 2013;17:R73.

5. Rosenberg AA, Haft JW, Bartlett R, Iwashyna TJ, Huang SK, Lynch WR, et al. Prolonged duration ECMO for ARDS: futility, native lung recovery, or transplantation? ASAIO J. 2016;59:642-50.

6. Peek GJ, Mugford M, Tiruvoipati R, Wilson A, Allen E, Thalanany MM, et al. Efficacy and economic assessment of conventional ventilatory support versus extracorporeal membrane oxygenation for severe adult respiratory failure (CESAR): a multicentre randomised controlled trial. Lancet. 2009;374:1351-63.

7. Lee YJ, Kim DJ, Kim JS, Lee J-H, Lee C-T, Jheon S, et al. Experience and results with VV-ECMO for severe acute respiratory failure: weaning versus nonweaning. ASAIO J. 2016;61:184-9. 
8. Posluszny J, Rycus PT, Bartlett RH, Engoren M, Haft JW, Lynch WR, et al. Outcome of adult respiratory failure patients receiving prolonged ( $\geq 14$ days) ECMO. Ann Surg. 2016;263:573-81.

9. Buchtele N, Schellongowski P, Bojic A, Hermann A, Robak O, Lamm W, et al. Successful weaning from 65-day extracorporeal membrane oxygenation therapy in influenza-associated acute respiratory distress syndrome. Int J Artif Organs. 2016;39:249-52.

10. Moon SM, Lee H, Moon JH, Kim HK, Park JE, Byeon S, et al. Prolonged maintenance of VV ECMO for 104 days with native lung recovery in acute respiratory failure. ASAIO J. 2016. https ://doi.org/10.1097/MAT.0000000000000293.

11. Lindholm J, Palmer K, Frenckner B. Long-term ECMO treatment in Jehovah's Witness patient without transfusions. Perfusion. 2012;27:332-4.

12. Brotfain E, Koyfman L, Toledano R, Borer A, Fucs L, Galante $\mathrm{O}$, et al. Positive fluid balance as a major predictor of clinical outcome of patients with sepsis/septic shock after ICU discharge. Am J Emerg Med. 2016;34:2122-6.

13. Besen BAMP., Taniguchi LU. Negative Fluid Balance in Sepsis: When and How? Shock. 2017;47(1S Suppl 1): 35-40.

14. Barbaro RP, Odetola FO, Kidwell KM, Paden ML, Bartlett RH, Davis MM, et al. Association of hospital-level volume of extracorporeal membrane oxygenation cases and mortality. Analysis of the Extracorporeal Life Support Organization Registry. Am J Respir Crit Care Med. 2015;191:894-901.

15. McCarthy FH, McDermott KM, Spragan D, Hoedt A, Kini V, Atluri $\mathrm{P}$, et al. Unconventional volume-outcome associations in adult extracorporeal membrane oxygenation in the United States. Ann Thorac Surg. 2016;102:489-95.

16. Fan E, Gattinoni L, Combes A, Schmidt M, Peek G, Brodie D, et al. Venovenous extracorporeal membrane oxygenation for acute respiratory failure. Intensive Care Med. 2016;42:712-24. 